\title{
A novel design in output tracing for nonlinear systems via the first and second time sliding mode control
}

\author{
BehzadSalari, Saeid haji \\ Student of Master Education, Electricity Control, Dar-al Fonoun Non-profit University, Qazvin,Iran. \\ Salarib66@gmail.com \\ Department of Technical and Engineeringkhanehkargarelmikarbordi,Qazvin,Iran. \\ Saeid.h60@gmail.com
}

\begin{abstract}
The problem of output tracing for nonlinear, non-minimum phase systemswill be surveyed in this article. A cascade form control structure will be presented, for the desirable output tracing during the stabilization of inner dynamics in a limited time that conjugates the first and second times of sliding mode methods together.This method is converged under the complete asymptotically feedback.Comparing to the other methods, this method main efficiency is that sliding mode dynamics of output tracing error variable has a lower rank and its adjustment is simpler consequently therefore the transient response variables have better properties. Theoric analysis and simulation results reveal the suggested method effictivness.
\end{abstract}

Keywords: output tracing, nonlinear non-minimum systems, sliding mode.

\section{Introduction}

In this study the lateral output detection problem will be studied for a category of undefined nonlinear systems that the output reference defined by an undefined nonlinear outer system with polynomial defined indicator. The suggested method improves the causality but it has the theoretical nature. Many efforts have been applied to address many of the issues mentioned above.(Cavallo and Natale,2014)Several control techniques have beenproposed for the noncausal case where the tracking referenceprofile is assumed to be known beforehand. An approximatesolution for a special class of systems and trajectories isproposed in. Exact tracking of a known trajectory givenby a noncausal system is achieved via a stable nonlinearinverse in.(Laghroucheet al,2014)In the authors address the problem ofasymptotic output tracking for a class of nonlinear uncertainsystems, where the output reference profiles are definedby an unknown linear exosystem with known characteristicpolynomial. The proposed method improves the causalitywith respect to the existing state of art, but the assumptionthat the characteristic polynomial of the exogenous systemis known makes its impact of mainly theoretical nature. Anextension to the result of has been proposed in, where the exogenous system, responsible for generating the output reference profile, is assumed to be unknown, but ofgiven order, and its characteristic polynomial is identified on-line via a higher-order sliding mode (HOSM) parameter observer and it is used for generating the referenceprofile for the internal state. A restriction of the method proposed in is the assumption of internal state availability that was later overcome in by designing a suitableobserver. In, internal state observation was tackled by including the presence of unknown inputs.(zare and kofigar,2015)

The lots of attempts have been done, solving the aforementioned problems. Some control methods were suggested for the nonobvious cases, assumed that the detection reference is determined in advance.(Gao and chen, 2007) An approximated solution is suggested for an especial class of systems and movement trajectories.

In this study a novel double loop cascade like control sketch is presented, combining the first and second order SMC methods. The ESSC method will be used for the calculation of inner unstable dynamics limited solution. The suggested solution protects the convergence and stability of current methods while it also makes the limited convergence time possible for the inner dynamic situations, caused high optimization.(Karamimolaei et al,2009) Moreover an undefined high frequency control matrix is considered in present study whereas in previous studies it was assumed that the matrix is completely defined.

\section{Problem Formulation}

$\mathrm{y}=\mathrm{G}_{\mathrm{p}}(\mathrm{s})[\mathrm{u}+\operatorname{de}(\mathrm{y}, \mathrm{t})]$,

where $u$ is the control input, $y$ is the output, $\operatorname{de}(y, t)$ is amatched input disturbance and $\mathrm{G}_{\mathrm{p}}(\mathrm{s})=$

$k_{p}\left(N_{p}(s) / D_{p}(s)\right)$, with $N_{p}(s)$ and $D_{p}(s)$ being monic polynomials of degreem and $n$, respectively. The following assumptions are made:

(A1) $\mathrm{G}_{\mathrm{p}}(\mathrm{s})$ is minimum phase, strictly proper and its parametersare unknown but belong to a known compact set. (A2)The degree $n$ of $D_{p}(s)$ is a known constant. (A3) $G_{p}(s)$ has 
known relative degree $n *:=n-m$. The above Assumptions(A1)-(A3) are usual in adaptive control [15]. Consider thefollowing additional assumptions:

(A4) The sign of the high frequency gain $k_{p} \neq 0$ isunknown.(A5) The disturbance de( $\left.y, t\right)$ is locally Lipschitz in $\mathrm{y}, \forall y$, and piecewise continuous in $\mathrm{t}, \forall t$. (A6) The nonlinear disturbance $\mathrm{d}_{\mathrm{e}}(\mathrm{y}, \mathrm{t})$ satisfies

$\left|\mathrm{d}_{\mathrm{e}}(\mathrm{y}, \mathrm{t})\right| \leq^{-} \operatorname{de}(\mathrm{y}, \mathrm{t}), \forall(y, t)$

imposed on $d_{e}$, e.g., $d_{e}(y, t)=y^{2}$. Since finite-time escape isnot precluded, a priori, $\left[0, t_{M}\right)$ is defined as the maximumtime interval of definition of a given solution, where $t_{M}$ may

be finite or infinite.

Reference Model: the reference model is given by

$\mathrm{y}_{\mathrm{m}}=\mathrm{M}(\mathrm{s}) \mathrm{r}=\left(\mathrm{k}_{\mathrm{m}} / \mathrm{D}_{\mathrm{m}}(\mathrm{s})\right) \mathrm{r}, \mathrm{k}_{\mathrm{m}}>0$,

where the reference signal $r(t)$ is assumed piecewise continuousand uniformly bounded, $\mathrm{D}_{\mathrm{m}}$ is a monic polynomialof degree $\mathrm{n}^{*}$.

Control Objective: the control objective is to achieveglobal or semi-global stability and convergence of the errorstate with respect to the origin of the error space. Inparticular, the tracking error

$e_{0}(t)=y(t)-y_{m}(t)$

should asymptotically tend to zero, i.e., exact tracking isrequired.(Cavallo and Natale,2014)

\section{Inner loop designing}

In the inner loop designing it is assumed that an undefined outer loop gives a vector signal as $v(\mathrm{t}) \in \mathrm{R}^{(\mathrm{n}-\mathrm{r})}$, that its time derivative has an upper bound depends on state and time.

Considering the usual model reference adaptive control(MRAC) approach, the output error $\mathrm{e}_{0}$ satisfy (Hsu et al,1994)

$\mathrm{e}_{0}=\mathrm{k}^{*} \mathrm{M}_{(\mathrm{s})}\left[\mathrm{u}-\mathrm{u}^{*}\right]$

where $\mathrm{k}^{*}=\mathrm{k}_{\mathrm{p}} / \mathrm{k}_{\mathrm{m}}$,

$\mathrm{u}^{*}:=\theta^{* \mathrm{~T}} \omega-\mathrm{W}_{\mathrm{d}}(\mathrm{s}) * \mathrm{~d}_{\mathrm{e}},(5)$

The signal $\mathrm{u}^{*}$ will be regarded as a matched inputdisturbance, thus an upper bound will be required. SinceWdis a proper stable transfer function and de satisfies Assumption (A6), then applying (costa and cunha,2003) to the convolution $\mathrm{W}_{\mathrm{d}}(\mathrm{s}) * \mathrm{~d}_{\mathrm{e}}(\mathrm{y}, \mathrm{t})$, one can find positiveconstants $\mathrm{cd}$, $\gamma \mathrm{dsuch}$ that $\left|\mathrm{W}_{\mathrm{d}}(\mathrm{s}) * \operatorname{de}(\mathrm{y}, \mathrm{t})\right| \leq^{\wedge} \mathrm{de}(\mathrm{t})$, where^ de is defined by

$\operatorname{de}(\mathrm{t}):=^{-} \mathrm{d}_{\mathrm{e}}(\mathrm{y}, \mathrm{t})+\mathrm{c}_{\mathrm{d}} \mathrm{e}^{-\gamma \mathrm{dt} *{ }^{-}} \mathrm{de}(\mathrm{y}, \mathrm{t})$.

Thus, from (5), $u$ *satisfies

$\left|\mathrm{u}^{*}(\mathrm{t})\right| \leq{ }^{-} \theta^{\mathrm{T}}|\omega(\mathrm{t})|+{ }^{\wedge} \mathrm{d}_{\mathrm{e}}(\mathrm{t}), \mathrm{t} €\left[0, \mathrm{t}_{\mathrm{M}}\right)$.

Consider the case of relative degree one, unknownsgn $\left(k_{p}\right)$, and nonlinear disturbances. This section will generalizethe results of (yan et al,2003) developed for linear plants.

The control law is defined by

$\mathrm{u}=\left[\mathrm{u}^{+}=-\mathrm{f}(\mathrm{t}) \operatorname{sgn}\left(\mathrm{e}_{0}\right)\right], \mathrm{t} € \mathrm{~T}^{+}$,

$\mathrm{u}^{-}=\mathrm{f}(\mathrm{t}) \operatorname{sgn}\left(\mathrm{e}_{0}\right), \mathrm{t} € \mathrm{~T}^{-}$,

where an appropriate monitoring function of the trackingerror $\mathrm{e}_{0}$ is used to decide when $\mathrm{u}$ would be switchedfrom $\mathrm{u}^{+}$to $\mathrm{u}^{-}$and vice versa, allowing the detection anywrong estimate of $\operatorname{sgn}\left(\mathrm{k}_{\mathrm{p}}\right)$. The sets $\mathrm{T}^{+}$and $\mathrm{T}^{-}$satisfy $\mathrm{T}^{+} \mathrm{UT}^{-}=\left[0, \mathrm{t}_{\mathrm{M}}\right)$ and $\mathrm{T}^{+} \cap \mathrm{T}^{-}=0$, and as will beshown in the following analysis, both $\mathrm{T}^{+}$and $\mathrm{T}^{-}$have 
theform $\left[t_{k}, t_{k+1}\right) U \cdots U[t j, t j+1)$. Here, $t_{k}$ or $t_{j} d e n o t e s$ theswitching time for $u$ and will be defined later. We refer tosuch switchings as control sign switchings.

According to (4), the modulation function $\mathrm{f}(\mathrm{t})$ should bea norm bound of $\mathrm{u}^{*}$. From (7), one possible choice is

$\mathrm{f}(\mathrm{t})={ }^{-} \theta^{\mathrm{T}}\left|\omega_{(\mathrm{t})}\right|+{ }^{\wedge} \mathrm{d}_{\mathrm{e}}(\mathrm{t})+\delta,(9)$

where $\delta$ is an arbitrary nonnegative constant. Consider forsimplicity $\mathrm{M}_{(\mathrm{s})}=\mathrm{k}_{\mathrm{m}} /\left(\mathrm{s}+\mathrm{a}_{\mathrm{m}}\right)\left(\mathrm{a}_{\mathrm{m}}, \mathrm{k}_{\mathrm{m}}>0\right)$. Then forsgn $\left(\mathrm{k}_{\mathrm{p}}\right)$ known, one chooses the control $\mathrm{u}^{+}$or $\mathrm{u}^{-}$, accordingto $\mathrm{k}_{\mathrm{p}}>0$ or $\mathrm{k}_{\mathrm{p}}<0$, respectively. Now, $\mathrm{e}_{0}$ satisfiese

$\dot{\varepsilon}_{0}(\mathrm{t})=-\mathrm{a}_{\mathrm{m}} \varepsilon_{0}(\mathrm{t})+\mathrm{k}_{\mathrm{p}}\left[\mathrm{u}(\mathrm{t})-\mathrm{u}^{*}(\mathrm{t})\right]+\pi(\mathrm{t})$

where $\pi(t)$ denotes a transient term due to initial conditionsof the observable but not controllable subsystem of thenonminimal realization $\left(A_{c}, b_{c}, h_{c}^{T}\right)$ of $M_{(s)}$ in (4), used

in MRAC theory [15]. Now, noting that $\operatorname{sgn}\left(u-u^{*}\right)=-\operatorname{sgn}\left(e_{0}\right)$, if the correct control direction is used and $f(t)$

$>\left|u^{*}\right|$, then by using the Comparison Theorem [13], $|e 0|$ is

bounded by the solution of the following differential equation

$\xi^{\cdot}(\mathrm{t})=-\mathrm{a}_{\mathrm{m}} \xi(\mathrm{t})+\pi(\mathrm{t}), \forall \mathrm{t} \epsilon\left[\mathrm{t}_{0}^{-}, \mathrm{tM}\right), \xi\left(\mathrm{t}_{0}^{-}\right)=\mathrm{e}_{0}\left(\mathrm{t}^{-}{ }_{0}\right)$

i.e., $\forall t \geq\left[{ }^{-} t_{0}, t_{M}\right)$, one has

$\left.\left|\mathrm{e}_{0}(\mathrm{t})\right| \leq|\xi(\mathrm{t})| \leq \mathrm{e}_{\mathrm{m}}^{-\mathrm{a}}{ }^{(\mathrm{t}-.}{ }_{0}\right)\left|\mathrm{e}_{0}\left({ }^{-} \mathrm{t}_{0}\right)\right|+\mathrm{c}_{0} \mathrm{e}^{-\delta \mathrm{t}}$

where ${ }^{-} t_{0}$ denotes some initial time.

Based on (12), consider the auxiliary function $\phi_{\mathrm{k}}$ defined

as follows:

$\phi_{\mathrm{k}}(\mathrm{t})=\mathrm{e}_{\mathrm{m}}^{-\mathrm{a}}{ }_{\mathrm{k}}^{(\mathrm{t}-\mathrm{t})}\left|\mathrm{e}_{0}\left(\mathrm{t}_{\mathrm{k}}\right)\right|+(\mathrm{k}+1) \mathrm{e}^{-\mathrm{tk}+1}$,

$\mathrm{t} €\left[\mathrm{t}_{\mathrm{k}}, \mathrm{t}_{\mathrm{M}}\right), \mathrm{t}_{0}:=0,(\mathrm{k}=0,1, \ldots)$.

The monitoring function $\phi_{\mathrm{m}}$ can be defined as

$\phi_{\mathrm{m}}(\mathrm{t}):=\phi_{\mathrm{k}}(\mathrm{t}), \forall \mathrm{t} €\left[\mathrm{t}_{\mathrm{k}}, \mathrm{t}_{\mathrm{k}+1}\right)\left(€\left[0, \mathrm{t}_{\mathrm{M}}\right)\right)$

The motivation behind the introduction of $\phi_{\mathrm{m}}$ is that $\pi$ isnot available for measurement. Reminding that the inequality $(12)$ holds if the $\operatorname{sgn}\left(\mathrm{k}_{\mathrm{p}}\right)$ is correctly estimated, it seemsnatural to use $\xi$ as a benchmark to decide whether a switchingof $u$ is needed. However, since $\pi$ is not available, one has touse $\phi_{\mathrm{m}}$ to replace $\xi$ and invoke the switching of $\phi_{\mathrm{m}}$. Note that from (14), one always has $\left|\mathrm{e}_{0}\left(\mathrm{t}_{\mathrm{k}}\right)\right|<\phi_{\mathrm{k}}\left(\mathrm{t}_{\mathrm{k}}\right)$ at $t=\mathrm{t}_{\mathrm{k}}$.

Hence, the switching time $t_{k}$ for $u$ from $\mathrm{u}^{-}$to $\mathrm{u}^{+}\left(\right.$or $\mathrm{u}^{+}$to $\left.\mathrm{u}^{-}\right)$is well-defined (for $\mathrm{k} \geq 0$ ):

$\mathrm{t}_{\mathrm{k}+1}=[\min \{t>t k:|e 0(t)|=\phi k(t)\}$, if it exists

$t_{M}$, otherwise

\subsection{Main Result for $n *=1$}

Theorem 1: Assume that (A1)-(A6) hold. Consider thesystem defined by (1), (2) and (8) and the modulationfunction given in (9). Then, the control sign switchings, driven by the monitoring function (14), will stop after afinite number of switchings and both the tracking error $\mathrm{e}_{0}$ and the complete state $\mathrm{X}_{\mathrm{e}}$ will converge to zero at leastexponentially.

Proof: We only sketch the proof, which is divided inthree parts. First it is proved that the switching stops aftera finite number of switchings (avoiding finite-time escape),

since for some finite $\mathrm{k}^{*}$ the term $\left(\mathrm{k}^{*}+1\right) \mathrm{e}^{-\mathrm{t} /\left(\mathrm{k}^{*}+1\right)} \mathrm{of}(13)$ will allow $\phi_{\mathrm{k}}(\mathrm{t})$ to be an upper bound valid for $\xi$, in $(12)$, consequently no switching will occur after that. Secondif the control direction is correctly estimated or not, since $\phi_{\mathrm{k}}$ converges to zero exponentially $\mathrm{e}_{0}(\mathrm{t})$ will also convergeto zero, at least exponentially, avoiding finitetime escape.Finally, the convergence of the complete error state $\mathrm{X}_{\mathrm{e}}$ canbe shown by using the regular form for the state spacerealization of (4).

Corollary 1: In Theorem 1, the control sign switchingstops at a correct sign corresponding to the unknown sign ofthe control direction of the plant, i.e., for $\mathrm{t}>\mathrm{t}_{\mathrm{k}}{ }^{*}, \mathrm{u}=\mathrm{u}^{+}$, ifk $>0$ and $\mathrm{u}=\mathrm{u}^{-}$, otherwise. 
Proof: The proof is based on a reverse dynamics argument.We know that if the sign is correct all trajectories ofthe system converge to the origin of the error state space.

Reverse Dynamics Argument: Assume that the finalcontrol sign is incorrect. Then, if we reverse the time, i.e.,t $\rightarrow{ }^{-} t$, the resulting equations have the same stabilityproperties as those obtained with the right control sign andthus all trajectories from any initial condition would convergeto the origin, i.e., the origin would be a global sink in reversetime. Thus, in forward time, all trajectories not at the originwould diverge unboundedly. This is a contradiction, sinceby Theorem 1 the state converges to the origin. Thus, the ultimate control sign must be correct

\section{Outer loop designing}

Consider the internal dynamics bounded to manifold $\sigma=0$. The main idea for generalizing the previous case consistsin reducing the problem to the $n *=1$ case by the introduction of the operator

$\mathrm{L}(\mathrm{s})=\mathrm{sN}+\mathrm{aN}-1 \mathrm{sN}-1+\ldots+\mathrm{a}_{0}, \mathrm{~N}:=\mathrm{n}^{*}-1$

such that $G_{p} L_{(s)}$ be of relative degree one (or, equivalently,almost strictly positive real -ASPR) and ML(s) be $\mathrm{SPR}$ (or ASPR). However, $\mathrm{L}_{(\mathrm{s})}$ is non-causal and what can beactually implemented is an approximate realization of thisoperator. One approximation is $\mathrm{L}$ given by the linear leadfilter

$\mathrm{L}_{(\mathrm{s})}=\mathrm{L}_{(\mathrm{s})} / \mathrm{F}_{(\tau \mathrm{s})}, \mathrm{F}_{(\tau \mathrm{s})}=\left(\tau_{\mathrm{s}}+1\right)^{\mathrm{N}}$ and $\tau>0,(17)$

As will be shown, this approximation leads to global/semiglobalstability with respect a residual set of order $\mathrm{O}_{(\tau)}$. However, it is well known that such filters usually lead tocontrol chattering and nonzero residual tracking error due tothe phase lag introduced the time constant $(\tau)$. Alternatively,

$\mathrm{L}_{(\mathrm{s})}$ can be implemented by using the Levant's robust exactdifferentiators (RED) (Levant,2003)which potentially allows the exactestimate of the $\mathrm{e}_{0}$ derivatives. The problem is that suchdifferentiators are valid only locally and may lead to unstablebehavior with larger initial conditions(Nunes,2004).

In the proposed control strategy, see Figure $1, \mathrm{~L}_{(\mathrm{s})}$ isreplaced by a hybrid lead filter, named Global Robust ExactDifferentiator (GRED). In Fig. 1, $\alpha$ represents a switchinglaw. It is then possible to obtain a exact compensationof the relative degree while assuring global or semi-globalstability properties of the closed loop system. The controlsign is adjusted according to the monitoring function $\phi_{\mathrm{m}}$, asindicated in Fig. 1.

The control $u$ is defined as in (8), replacing $\mathrm{e}_{0}$ by ${ }^{\sim} \varepsilon_{0}:=\alpha^{-} \varepsilon_{0}+(1-\alpha) \varepsilon_{0}$ (see Fig. 1), i.e.,

$\mathrm{u}=\left[\mathrm{u}^{+}=-\mathrm{f}(\mathrm{t}) \operatorname{sgn}\left(\tilde{} \varepsilon_{0}\right), \mathrm{t} \in \mathrm{T}^{+}\right.$,

$\mathrm{u}^{-}=\mathrm{f}(\mathrm{t}) \operatorname{sgn}\left({ }^{\sim} \varepsilon_{0}\right), \mathrm{t} \in \mathrm{T}^{-},(18)$

The strategy for switching the control direction, accordingto a new monitoring function $\phi_{\mathrm{m}}$, will be redefined later on.

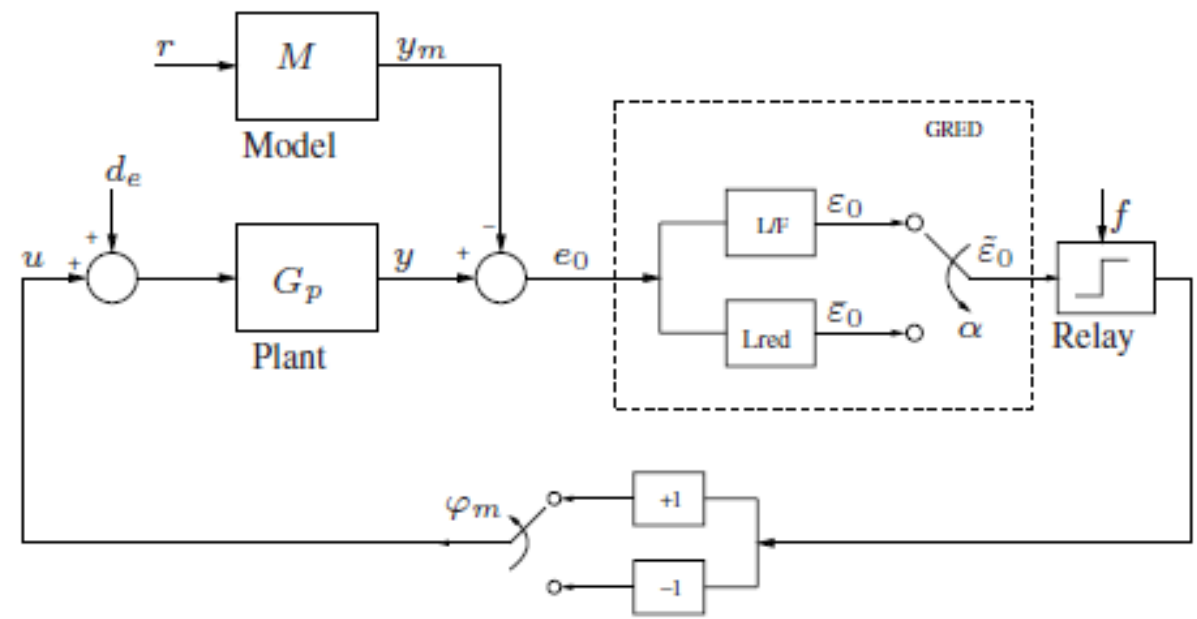

Fig1. Suggested Cascade-like controlling structure 


\section{Auxiliary Errors for Analysis and Design}

As explained above, assume that only the linear lead filteris active, i.e., ${ }^{2} \varepsilon_{0}=\varepsilon_{0}$. Then, from Figure 1 , one has

$\varepsilon_{0}=, \frac{L(s)}{F(\tau s)} \mathrm{e}_{0}$

which can be rewritten as

$\varepsilon_{0}=\mathrm{k} * \mathrm{ML}\left[\mathrm{u}-\mathrm{u}^{*}\right]+\beta_{\mathrm{U}}+\mathrm{e}_{\mathrm{F}}^{0}, \forall \mathrm{t} \in\left[0, \mathrm{t}_{\mathrm{M}}\right)$

where

$\beta_{\mathrm{U}}:=\mathrm{k}^{*} \mathrm{ML}_{(\mathrm{s})}\left[1-\mathrm{F}_{(\mathrm{ts})}\right] \mathrm{F}^{-1}(\tau \mathrm{s}) *\left(\mathrm{u}-\mathrm{u}^{*}\right)$ and

$\left|\mathrm{e}_{0}{ }^{\mathrm{F}}\right| \leq \mathrm{R}_{1 \mathrm{e}}{ }^{-\lambda \mathrm{ct}}+\mathrm{R}_{2} / \tau^{\mathrm{Ne}-\mathrm{t} / \tau} \leq \mathrm{R}_{\mathrm{a}} \mathrm{e}^{-\lambda \mathrm{a}(\mathrm{t}-\mathrm{te}(\tau))}$.

The positive constants $R_{1}, R_{2}, R_{a}$ andType equation here. $\lambda$ care independentof $\tau>0 ; \lambda_{c}$ is lower than the stability margin of $\mathrm{A}_{\mathrm{c}}$ and $0<\lambda_{\mathrm{a}}<\min \left(\lambda_{\mathrm{c}}, 1 / \tau\right)$, with $\tau>\tau$.

The first inequality in (22) holds $\forall \mathrm{t} \geq 0$, while the lastone holds only $\forall \mathrm{t} \geq \mathrm{t}_{\mathrm{e}}$ where $\mathrm{t}_{\mathrm{e}}$ is the peak extinctiontime, i.e., the smallest time value at which the inequality

$\mathrm{R}^{2} / \tau^{\mathrm{Ne}-\mathrm{t} / \tau} \leq \mathrm{R}_{2}, \forall \mathrm{t} \geq \mathrm{t}_{\mathrm{e}}(\tau), \forall \mathrm{R}_{2}$ is satisfied for a fixed valueof the parameter $\tau \in(0,1)$.

The constants $\mathrm{R}_{1}$ and $\mathrm{R}_{2}$ are linear combination of theinitial conditions $\mathrm{X}_{\mathrm{e}}(0)$ and $\mathrm{x}_{\mathrm{f}}(0)$, where $\mathrm{x}_{\mathrm{f}}$ is the state vectorof the realization $\left(\mathrm{A}_{\mathrm{f}} / \tau, \mathrm{B}_{\mathrm{f}} / \tau, \mathrm{C}_{\mathrm{f}} / \tau^{\mathrm{N}}, 1 / \tau^{\mathrm{N}}\right)$ with $\left(\mathrm{A}_{\mathrm{f}}, \mathrm{B}_{\mathrm{f}}, \mathrm{C}_{\mathrm{f}}, 1\right)$

being the canonical controllable realization of $\mathrm{L} / \mathrm{F}$ in (19).

By using this realization, peaking appears only in the output $\varepsilon_{0}$ while the state $\mathrm{x}_{\mathrm{f}}$ is peaking free.

\subsection{An Upper Bound for te(peak extinction time):}

It canbe easily concluded that te $(\tau)$ is uniformly bounded by aclass-K function of $\tau$. Moreover, there exist ${ }^{-} t_{\mathrm{e}}(\tau)$ $€ \mathrm{~K}$ such that

$\mathrm{t}_{\mathrm{e}}(\tau) \leq \mathrm{t}_{\mathrm{e}}(\tau)$

which can be obtained from the known upper bounds of theplant parameters.Considering the error system (4), (19), the following statevector $\mathrm{z}$ is used

$\mathrm{z}^{\mathrm{T}}:=\left[\mathrm{X}_{\mathrm{e}}^{\mathrm{T}}, \mathrm{X}_{\mathrm{f}}\right], \mathrm{z} \in \mathrm{IR}^{3 \mathrm{n}-2+\mathrm{N}}(24)$

The following inequality is a consequence of the continuityof the Filippov solutions and the particular state realizationassociated with $\mathrm{x}_{\mathrm{f}}$ :

$|\mathrm{z}(\mathrm{t})| \leq \mathrm{k}_{\mathrm{z} 0}|\mathrm{z}(0)|+\mathrm{V}(\tau)$

$\forall \mathrm{t} €[0, \mathrm{te}(\tau)] \mathrm{C}\left[0, \mathrm{t}_{\mathrm{M}}\right), \forall \tau €\left(0, \tau_{1}\right] ; 0<\tau_{1} \leq 1 ; \mathrm{V} € \mathrm{~K}$

and $\mathrm{k}_{\mathrm{z} 0}>0$ is a constant.

\subsection{Monitoring Function (n*> 1)}

The following lemma provides an upper bound for $\left|\varepsilon_{0}\right|$,valid if $\operatorname{sgn}\left(\mathrm{k}_{\mathrm{p}}\right)$ is known and $\mathrm{t} €\left[\mathrm{t}_{\mathrm{e}}, \mathrm{t}_{\mathrm{M}}\right)$, from which thenew monitoring function will be defined.

Lemma 1: Consider the I/O relationship

$\varepsilon(\mathrm{t})={ }^{-} \mathrm{M}(\mathrm{s})[\mathrm{u}+\mathrm{d}(\mathrm{t})]+\pi(\mathrm{t})+\beta(\mathrm{t}),(26)$

and any arbitrary initial time ${ }^{-} \mathrm{t}_{0} \geq 0$, where ${ }^{-} \mathrm{M}(\mathrm{s})={ }^{-} \mathrm{k} /\left(\mathrm{s}+{ }^{-} \alpha\right)\left(\mathrm{k},{ }^{-} \alpha>0\right), \mathrm{d}(\mathrm{t})$ is LI, $\beta(\mathrm{t})$ and $\pi(\mathrm{t})$ areabsolutely continuous, $\forall \mathrm{t} €\left[\mathrm{t}_{0}, \mathrm{t}_{\mathrm{M}}\right)$. Assume that $|\pi(\mathrm{t})| \leq \mathrm{Re}^{-\lambda(\mathrm{t}-\mathrm{t})}, \forall \mathrm{t} €\left[\mathrm{t}_{0}, \mathrm{t}_{\mathrm{M}}\right)$, where $\mathrm{R}, \lambda$ are positive constants.If $\mathrm{u}=-\mathrm{f}(\mathrm{t})$ $\operatorname{sgn}(\varepsilon)$, where the modulation function $\mathrm{f}(\mathrm{t})$ isLI and satisfies $\mathrm{f}(\mathrm{t}) \geq|\mathrm{d}(\mathrm{t})|, \forall \mathrm{t} €\left[\mathrm{t}_{0}, \mathrm{t}_{\mathrm{M}}\right)$, then the signal ${ }^{-} \mathrm{e}_{(\mathrm{t})}:=\varepsilon(\mathrm{t})-$ $\beta(\mathrm{t})-\pi(\mathrm{t})$ is bounded by (for any arbitrarytisuch that $\mathrm{t}_{0} \leq \mathrm{ti}<\mathrm{t}_{\mathrm{M}}$ and ${ }^{-} \alpha \lambda:=\min (\alpha, \lambda)$ )

$\left\lceil\mathrm{e}(\mathrm{t})|\leq| \varepsilon\left(\mathrm{t}_{\mathrm{i}}\right)-\beta\left(\mathrm{t}_{\mathrm{i}}\right) \mathrm{e}^{-. \alpha(\mathrm{t} t \mathrm{ti})}+\mathrm{R}_{\mathrm{e}}^{-. \alpha \lambda\left(\mathrm{t}^{-.}+0_{0}\right)}+\prod \beta_{\mathrm{t}}, \mathrm{t}_{0}^{-} \prod\right.$. 
Reminding that $\varepsilon_{0}=\beta_{\mathrm{U}}+{ }^{-} \mathrm{e}_{0}+\mathrm{e}^{0}{ }_{\mathrm{F}}$ then $\left|\varepsilon_{0}\right| \leq\left|\beta_{\mathrm{U}}\right|+{ }^{-} \mathrm{e}_{0}|+| \mathrm{e}_{\mathrm{F}}^{0} \mid$. Now, applying Lemma 1 to (20), considering $\mathrm{t}_{0}:=$ $\mathrm{t}_{\mathrm{e}}$ and $\mathrm{ML}_{(\mathrm{s})}=\mathrm{k}_{\mathrm{m}} /\left(\mathrm{s}+\mathrm{a}_{\mathrm{m}}\right)$ (for simplicity), and

from (22) one has $\forall \mathrm{t}, \mathrm{t}_{\mathrm{k}}$ such that $\left(\mathrm{t}_{\mathrm{M}}>\mathrm{t} \geq \mathrm{t}_{\mathrm{k}} \geq \mathrm{t}_{\mathrm{e}}\right)$,

$\left|\varepsilon_{0}(\mathrm{t})\right| \leq\left(\left|\varepsilon_{0}\left(\mathrm{t}_{\mathrm{k}}\right)\right|+\left|\beta_{\mathrm{U}}\left(\mathrm{t}_{\mathrm{k}}\right)\right|\right) \mathrm{e}^{-\mathrm{am}(\mathrm{t}-\mathrm{tk})}+$

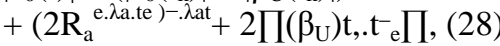

where ${ }^{-} \lambda_{\mathrm{a}}=\min \left\{\mathrm{a}_{\mathrm{m}}, \lambda_{\mathrm{a}}\right\}$. Note that, according to Lemma 1 ,

(28) is valid for the modulation function $\mathrm{f}(\mathrm{t})$ given in (9).Consider the available signal

$\beta_{\mathrm{U}}^{-}=2 \mathrm{k}^{-} * \tau \mathrm{W}_{\beta}(\mathrm{s}) * \mathrm{f}(\mathrm{t})$

where $\tau \mathrm{W}_{\beta}(\mathrm{s})$ is a first order approximation filter $(\mathrm{FOAF},[19])$ for the transfer function $\mathrm{ML}_{(\mathrm{s})}[1-\mathrm{F}(\tau \mathrm{s})]$

$\mathrm{F}^{-1}(\tau \mathrm{s})$. Note that, from $(21),(18)$ and $(9)$, one has $\beta_{\mathrm{U}}(\mathrm{t}) \leq \beta_{\mathrm{U}}(\mathrm{t})$

$\left(\forall \mathrm{t} €\left[0, \mathrm{t}_{\mathrm{M}}\right)\right)$. Let

$\phi_{\mathrm{k}}(\mathrm{t}):=\left(\left|\varepsilon_{0}\left(\mathrm{t}_{\mathrm{k}}\right)\right|+\beta_{\mathrm{U}^{-}}\left(\mathrm{t}_{\mathrm{k}}\right)\right) \mathrm{e}^{-\mathrm{am}(\mathrm{t}-\mathrm{tk})}+$

$+\mathrm{a}(\mathrm{k}) \mathrm{e}^{-\lambda \mathrm{ct}}+2 \prod\left(\beta_{\mathrm{U}^{-}}\right) \mathrm{t} \prod$

$\forall t €\left[\mathrm{t}_{\mathrm{k}}, \mathrm{t}_{\mathrm{M}}\right)$, with $\lambda \operatorname{cin}(22)$ and $\mathrm{a}(\mathrm{k})$ is any positivemonotonically increasing unbounded sequence. The monitoringfunction for $\mathrm{n}^{*}>1 \phi_{\mathrm{m}}$ is defined by

$\phi_{\mathrm{m}}(\mathrm{t}):=\phi_{\mathrm{k}}(\mathrm{t}), \forall \mathrm{t} €\left[\mathrm{t}_{\mathrm{k}}, \mathrm{t}_{\mathrm{k}+1}\right) \mathrm{C}\left[0, \mathrm{t}_{\mathrm{M}}\right)$.

Note that $\phi_{\mathrm{m}}$ is discontinuous in $\mathrm{t}$. The switching time $\mathrm{t}_{\mathrm{k}}$ for $\mathrm{u}$ from $\mathrm{u}^{-}$to $\mathrm{u}^{+}\left(\mathrm{or}^{+}\right.$to $\left.\mathrm{u}^{-}\right)$is well-defined by: $\mathrm{t}_{\mathrm{k}}+1:=\left[\min \left\{\mathrm{t}>\mathrm{t}_{\mathrm{k}}:\left|\varepsilon_{0}(\mathrm{t})\right|=\phi_{\mathrm{k}}(\mathrm{t})\right\}\right.$, if it exists ,

$t_{M}$, otherwise,

where $\mathrm{k} \geq 1, \mathrm{t}_{0}:=0$ and $\mathrm{t} 1:=\mathrm{t}_{\mathrm{e}}{ }^{-}$. For convenience, $\phi_{0}:=0, \forall \mathrm{t} €\left[\mathrm{t}_{0}, \mathrm{t}_{1}\right)$. The following proposition follows directlyfrom the definition of the monitoring function $\phi_{\mathrm{m}}$, in (31).

Proposition 1: Let $\mathrm{k} \geq 1$ be the largest switching indexof the monitoring function (31), such that $t_{k} \in\left[0, t_{M}\right)$, thenthe auxiliary error $\varepsilon_{0}(\mathrm{t})$ is bounded by

$\left|\varepsilon_{0}(\mathrm{t})\right| \leq \phi_{\mathrm{m}}(\mathrm{t}), \forall \mathrm{t} €\left[\mathrm{t}_{1}, \mathrm{t}_{\mathrm{M}}\right)$

\section{Dynamic stability of sliding mode}

Now we are going to analyze the stability of system path properties that are bounded to $\sigma=0$ manifold and under the extra situation and using that, determine a suitable criterion for the selection of design matrix $\mathrm{D}$.

$\left(\mathrm{G}_{1}-\mathrm{G}_{2} \mathrm{D}\right) \mathrm{e}_{\varepsilon 1}+\varepsilon c=\mathrm{G}_{2} \mathrm{H}_{\mathrm{v}}$

The below equivalent dynamic will be obtained:

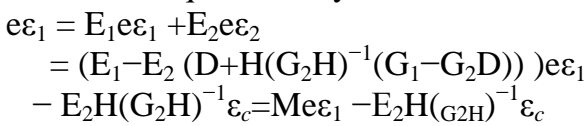

It describes the system movement in sliding mode situations that $\sigma=0$ and $\dot{e}_{\eta}=e_{\eta}=0$ simultaneously. The last term of input is bounded constantly that converges to zero asymptotically which doesn't affect the asymptotic stability. This depends on $\mathrm{D}$ and $\mathrm{H}$ matrices for the below matrix from 22.

$\mathrm{M}=\mathrm{E}_{1}-\mathrm{E}_{2}\left(\mathrm{D}+\mathrm{H}\left(\mathrm{G}_{2} \mathrm{H}\right)^{-1}\left(\mathrm{G}_{1}-\mathrm{G}_{2} \mathrm{D}\right)\right)$

Rewrite the relation 23 as below:

$\mathrm{M}=\mathrm{E}_{1}-\mathrm{E}_{2} \mathrm{H}\left(\mathrm{G}_{2} \mathrm{H}\right)^{-1} \mathrm{G}_{1}+\mathrm{E}_{2}\left(\mathrm{H}\left(\mathrm{G}_{2} \mathrm{H}\right)^{-1} \mathrm{G}_{2}-\mathrm{I}\right)^{\mathrm{D}}(37)$

Let's consider another assumption.

Assumption 5: can find matrix $\mathrm{H}$ so the below matrices create a controllable pair.

$\mathrm{E}_{1}-\mathrm{E}_{2} \mathrm{H}\left(\mathrm{G}_{2} \mathrm{H}\right)^{-1} \mathrm{G}^{1}$ and $\mathrm{E}_{2}\left(\mathrm{H}\left(\mathrm{G}_{2} \mathrm{H}\right)^{-1} \mathrm{G}_{2}-\mathrm{I}\right)$

Considering the upper assumption, it could be resulted that designed matrix $\mathrm{D}$ can be chosen randomly for the putting of especial amount of matrix $\mathrm{M}$ in relation 24. It must be mentioned that assumption 5 is necessary but isn't enough. But in this way the $\mathrm{M}$ range couldn't be assigned.

\section{Simulation Results}

The suggested algorithm usefulness is revealed by the simulation. A non-minimum 5 order system MIMO phase is considered, stimulated by two harmonic signal and the system is solved using the below. 
This section presents an illustrative simulation examplewhich highlights the performance of the proposed controlscheme for a nonlinear plant with relative degree $n *=3$.

Example 1: Consider an open-loop unstable plant withtransfer function given by:

$\mathrm{Gp}_{(\mathrm{s})}=\frac{1}{(s+2)(s+1)(s-1)}$,

Beingcontrolled by the VS-MRAC controller of Figure 1 andunder the action of a nonlinear input disturbance $\mathrm{d}_{\mathrm{e}}(\mathrm{y}, \mathrm{t})=\mathrm{y}^{2}+\operatorname{sqw}(5 \mathrm{t})$, where sqw denotes a unit square wave. Thereference model is $\mathrm{M}_{(\mathrm{s})}=\frac{4}{(s+2) 3}$ and the linear lead filteris given in (17) with $\mathrm{L}_{(\mathrm{s})}=(\mathrm{s}+2)^{2}$ and $\tau=$

0.01 . Themonitoring function is obtained from (31) with $\mathrm{a}(\mathrm{k})=\mathrm{k}+1$ and ${ }^{-} \lambda \mathrm{c}=0.5$. The plant initial conditions are $\mathrm{y}(0)=2, \mathrm{y}^{\cdot}(0)=0$ and $\mathrm{y} \cdot(0)=2$ and the feedback is positive at $\mathrm{t}=0$

(wrong control direction).

Figure 2 corresponds to a simulation result when thereference signal is a sinusoid of amplitude 1 and frequency $1 \mathrm{rad} / \mathrm{s}$. The convergence of the plant output signal to the model reference output is clear. Figure 3 (a) shows that justone switching in the control sign was need (first jump of $\phi_{\mathrm{m}}$ when it meets $\tilde{\varepsilon}_{0}$ ). After that, the control direction is correctly identified and the auxiliary error $\tilde{\varepsilon}_{0}$, as well as thetracking error, vanish in finite time. Note that the seconddiscontinuous-like change of $\phi_{\mathrm{m}}$ is not due to a changebetween $\mathrm{u}^{+}$and $\mathrm{u}^{-}$. It is due to the $\prod\left(\beta_{\mathrm{U}}{ }^{-}\right)_{\mathrm{t}}$ Пterm in (30).led to quite reasonable transient behavior in our simulationsin contrast to the Nussbaum gain approach.

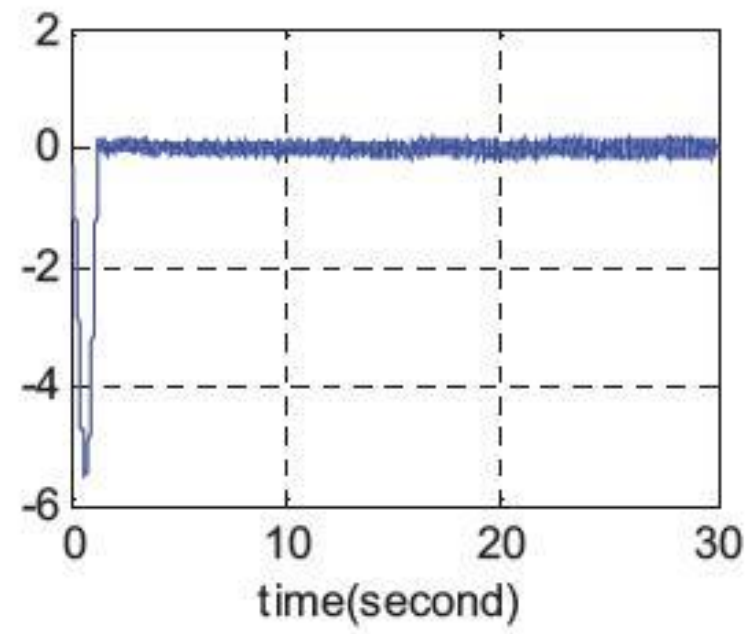

Fig2- First output vector $\xi_{1}$ (in complete scale)

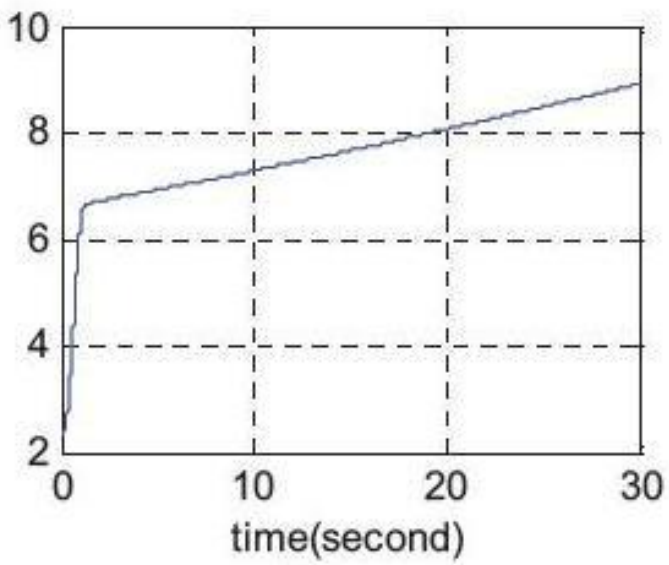

Fig 3- First output vector $\xi_{1}$ (maximized) 
The figures 2 to 4 show the performance, high accuracy and authenticity of controller output detection. Output profile discontinuity affects the both ESSC filter and internal dynamic detection (see figure 5). Finally the figures 6 show the assessment of sliding variable boundary layer for outer loop $\sigma$.

\section{Conclusion}

The outer control detection was solved for a set of nonlinear non-minimum phase systems, using the fist/second order hybrid method of sliding mode.Despite of using the detector in present situations, the creation of one solution that doesn't need the knowing of Q matrix is under study. This is an important and controversial problem that needs the complete review in ESSC method.

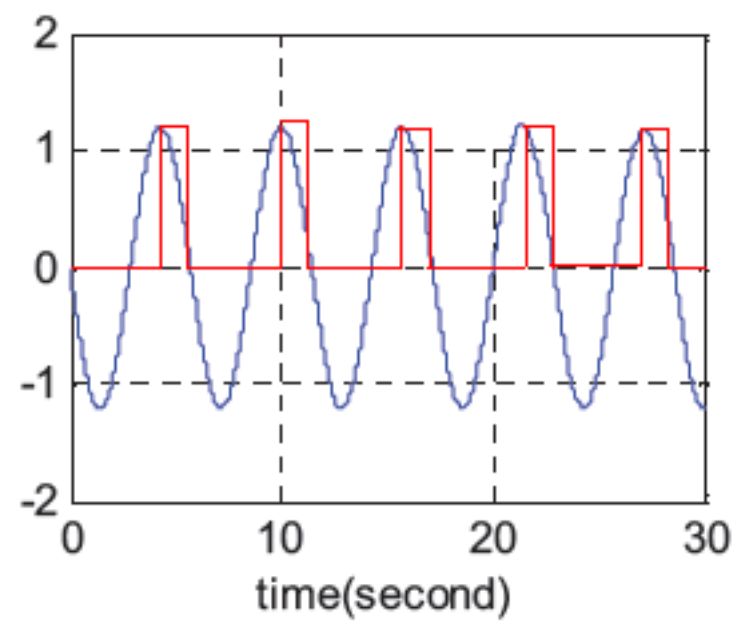

Fig4. Second output vector $\xi_{2}$ (maximized)

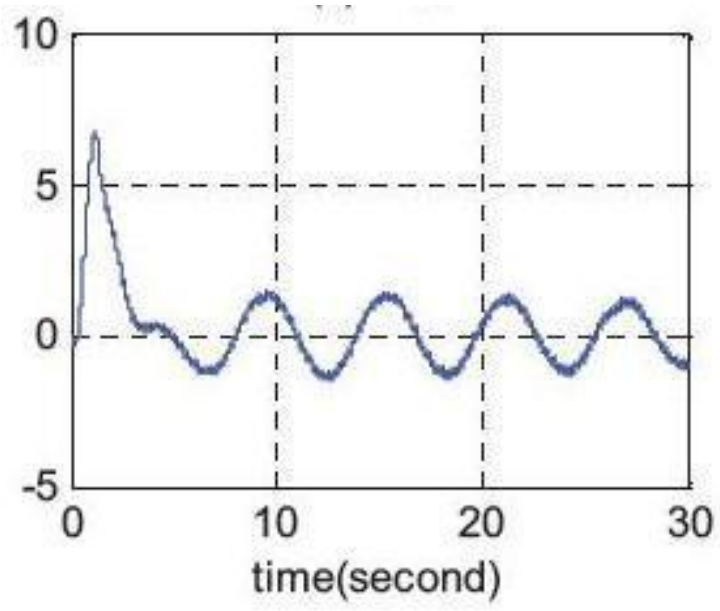

Fig5. Internal dynamic $\eta$ and SSC filter performance, means the $\theta_{\text {input and }} \hat{\eta}_{C}$ output. 


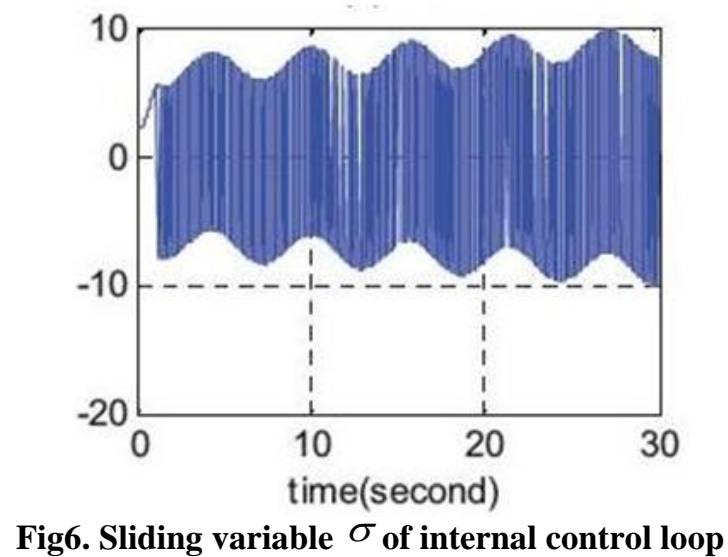

\section{References}

[1]. A.Aboei, M.R. jahedmotlagh, and Z.Rahmanicharati,"A chaotic system new light with an equilibrium and stabilization using linear feedback"control journal, volume3, No 1,pp 37-46,spring 2009.

[2]. Alessandro Pisano, Simon Baev, Domenico Salimbeni, Yuri Shtessel and Elio Usai,A new approach to causal output tracking for non-minimum phasenonlinear systems via combined first/second order sliding mode control,European Control Conference (ECC) July 17-19, 2013, Zürich, Switzerland,2013.

[3]. A.Karamimolaei,N.periz,M.H.Modirshanechi," Sliding mode control of nonlinear systems with adaptive swiching comparative" The control group ferdowsi university of mashhad, control journal, scientific information database,volume4, winter 2009.

[4]. L. Yan, L. Hsu, R. R. Costa and F. Lizarralde, "Variable StructurModel Reference Adaptive Control for Systems with Unknown HighFrequency Gain", 2003 Conference on Decision and Control, Hawaii,pp. 3525-3530, 2003.

[5]. T. Gao, G. Chen, Z. Chen, and S. Chen, "The generation and circuitimplementation of a new hyperchaos uponLorenz system," PhysicsLetters A, vol. 361, no. 1, pp. 78-86, Jan. 2007.

[6]. Cavallo A. and Natale C, "Output feedback control based on a high-order sliding manifold approach", IEEE Transaction on Automatic Control, 48, 3, 469-472,2014.

[7]. L. Hsu, A. D. Ara'ujo, and R. R. Costa, "Analysis and design of I/O based variable structure adaptive control," IEEE Trans. Aut. Contr., vol. 39, no. 1, pp. 4-21, 1994.

[8]. L. Hsu, Tiago R. Oliveira and Alessandro J. Peixoto,Sliding Mode Control of Uncertain Nonlinear Systems with Arbitrary Relative Degree and Unknown Control Direction, Proceedings of the 2006 International Workshop on Variable Structure SystemsAlghero, Italy, June 5-7, 2006.

[9]. E. V. L. Nunes, L. Hsu and F. Lizarralde, "Globally Stable Output-Feedback Sliding Mode Control with Asymptotic Exact Tracking", inAmerican Control Conference, Boston, Ma, 2004, pp. 638-643.

[10]. E. V. L. Nunes, L. Hsu and F. Lizarralde, "Output-Feedback SlidingMode Control for Global Asymptotic Tracking of Uncertain Systemsusing Locally Exact Differentiators", in American Control Conference,

[11]. Minneapolis, accepted, 2006. ACC06 Submission No. 502 Title:Author(s): Eduardo Vieira LeaoNunes*, Liu Hsu, Fernando Lizarralde,2006.

[12]. A. Levant, "Higher-order sliding modes, differentiation and outputfeedbackcontrol," Int. J. Contr., vol. 76, no. 9, pp. 924-941, 2003.

[13]. L. Hsu, R. R. Costa, and J. P. V. S. Cunha. Model-reference outputfeedbacksliding mode controller for a class of multivariable nonlinearsystems. Asian Journal of Control, 5(4):543-556, 2003.

[14]. C. Wang, X. Zhang, Y. Zheng, and Y. Li, "A new modifiedhyperchoaticLü system," Physica A: StatisticalMechanics and ItsApplications, vol. 371, no. 2, pp. 260-272, Nov. 2006.

[15]. Levant A., "Sliding order and slidingaccuracy in sliding mode control", InternationalJournal of Control, 58, 1247-1263,2012.

[16]. Laghrouche S., Plestan F. and Glumineau A., "Higher order sliding mode control based onoptimal linear quadratic control", European Control Conference, 2014.

[17]. W. Wu, Z. Chen, and Z. Yuan, "The evolution of a novel four -dimensional autonomous system: among 3 - torus, limit cycle, 2 torus, chaos, and hyperchaos," Chaos, Solitons, and Fractals,vol. 39, no. 5,pp. 2340-2356, Mar. 2009.

[18]. K.Zare and H.R.Kofigar,"Second-order adaptive sliding mode control nonlinear system two inputs,two outputs and indefinite use of helicopters in two degrees of freedom" March 2015.

[19]. H. Wang, Z. Z. Han, Q. Y. Xie, and W. Zhang, "Sliding modecontrol for chaotic systems based on LMI," Communications inNonlinear Science and Numerical Simulation, vol. 14, no. 4,pp. 1410-1417, Apr. 2009. 